\title{
THE EFFECTIVENESS OF TRIPLE-DOSE ALBENDAZOLE IN COMPARISON WITH MEBENDAZOLE FOR THE TREATMENT OF TRICHURIASIS IN CHILDREN
}

\section{SALEHA SUNGKAR ${ }^{1}$, FANNY P. IRMAWATI ${ }^{1}$, ROSE A. HASWINZKY ${ }^{1}$, YASMINE A. DWINASTITI ${ }^{1}$, SRI WAHDINI ${ }^{*}$, NURHADI E. FIRMANSYAH' ${ }^{1}$, ROBIATUL ADAWIYAH ${ }^{1}$, STANLEY BUNTARAN ${ }^{2}$, ARIA KEKALIH ${ }^{3}$, GLADYS KUSUMOWIDAGDO ${ }^{1}$}

1Department of Parasitology Faculty of Medicine Universitas Indonesia, Jakarta, Indonesia, ${ }^{2}$ Jakarta Medical Center Hospital, Jakarta, Indonesia, ${ }^{3}$ Department of Community Medicine, Faculty of Medicine, Universitas Indonesia, Jakarta, Indonesia

Email: sriwahdini@yahoo.com

Received: 15 Dec 2018, Revised and Accepted: 10 Mar 2019

\section{ABSTRACT}

Objective: Trichuriasis is difficult to treat with single-dose anthelmintic. Although a higher cure rate (CR) can be achieved by treatment with tripledose albendazole and mebendazole, the results of studies are inconsistent. This study aimed to evaluate the effectiveness of triple-dose albendazole and mebendazole in treating trichuriasis.

Methods: A randomized controlled trial was conducted in a primary school in the Pandeglang District, Banten Province, Indonesia in July-August, 2018; 382 children were recruited. Stools were collected and examined microscopically using the Kato-Katz method to identify Trichuriasis eggs. Children positive for Trichuris trichiura were randomized and divided into two groups. One was given a triple dose of $400 \mathrm{mg}$ albendazole and the other a triple dose of $500 \mathrm{mg}$ mebendazole. On day 14 after treatment, stools were reexamined to calculate CR and the egg reduction rate (ERR). Data were analyzed using SPSS version 20.

Results: The prevalence of soil-transmitted helminth infection was $42 \%$, and that of trichuriasis and ascariasis was $25.1 \%$ and $29.8 \%$. There was a significant difference (Wilcoxon test, $\mathrm{P}<0.01$ ) in the intensity of infection before and after intervention. Both groups showed high values of $\mathrm{CR}$ (mebendazole: 95.2\%, albendazole: 85.4\%; Fisher's exact test, P = 0.125) and ERR (mebendazole: 99\%, albendazole: 96\%; Mann-Whitney test, P = 0.110). There was no significant difference in CR and ERR between the two groups.

Conclusion: Triple-dose albendazole was as effective as triple-dose mebendazole in treating trichuriasis.

Keywords: Trichuriasis, Albendazole, Mebendazole, Cure rate, Egg reduction rate

(c) 2019 The Authors. Published by Innovare Academic Sciences Pvt Ltd. This is an open access article under the CC BY license (http://creativecommons. org/licenses/by/4. 0/) DOI: http://dx.doi.org/10.22159/ijap.2019.v11s6.33559

\section{INTRODUCTION}

Trichuriasis is a helminth infection caused by the soil-transmitted helminth (STH), Trichuris trichiura. This disease is a community health problem, especially in areas where poverty is prevalent, along with a low socioeconomic status and unhealthy hygiene habits $[1,2]$. In the Sumba Barat Daya District, Indonesia, the prevalence of trichuriasis is as high as $64 \%$, and the disease is of great concern throughout Indonesia [3, 4].

T. trichiura lives in the colon, specifically in the caecum where it threads itself into the colonic mucosa and ingests superficial tissue leading to tissue injury and bleeding. The worm inserts its cephalic portion into the intestine, which then irritates and initiates inflammatory reactions of the mucosa. These events can be asymptomatic, but can also manifest as anorexia, epigastric pain, nausea, vomiting, diarrhea, bloating, and frequent flatulation. In the case of severe infection, the feces may contain blood and mucus, thus causing anemia and dysentery syndrome when untreated. It may also lead to rectal prolapse due to hard straining during defecation. In cases of chronic infection, T. trichiura can result in malnutrition, stunting, and cognitive problems [1].

Because of the high prevalence of trichuriasis and the severe impact of chronic infection, the World Health Organization (WHO) [5]recommends the administration of a single-dose of $400 \mathrm{mg}$ albendazole or $500 \mathrm{mg}$ mebendazole every six months in areas with a trichuriasis prevalence over $50 \%$ and once a year, if the prevalence increases $20 \%$. However, both drugs possess low effectiveness against trichuriasis (30\%).

Even with current drug development, treating trichuriasis is very challenging, as there is no drug with a high effectiveness in killing $T$. trichiura. A single-dose of $400 \mathrm{mg}$ albendazole and $500 \mathrm{mg}$ mebendazole only results in a $30-50 \%$ cure rate (CR). The CR can be increased by giving triple doses (three days in a row) of albendazole and mebendazole [6]. Some studies have reported that the effectiveness of triple-dose mebendazole was better than triple-dose albendazole, although the results were not consistent between the studies $[7,8]$. Therefore, it is necessary to investigate further the effectiveness of a triple dose of $400 \mathrm{mg}$ albendazole and $500 \mathrm{mg}$ mebendazole against trichuriasis.

\section{MATERIALS AND METHODS}

This study was approved by the Ethical Committee on Health Research, Faculty of Medicine, Universitas Indonesia (protocol No. 626/UN2. F1/ETIK/V/2018). We conducted a randomized controlled trial (RCT) that was preceded by a cross-sectional study to determine the prevalence of trichuriasis. The study was conducted at a primary school in Panimbang Village, Pandeglang District, Banten Province (total sampling), and data were collected in July-August 2018. The subjects' characteristics, the prevalence of trichuriasis, intensity of infection, CR, and egg reduction rate (ERR) were recorded.

Subjects were children aged 6-12 y who tested positive for $T$. trichiura eggs based on fecal examination. Parents consented to their children's participation in this study. Children with fever were excluded. To determine the necessary number of study subjects, screening of trichuriasis prevalence was performed, and the number was calculated based on the formula:

$$
\begin{aligned}
& \mathrm{n}=\frac{\mathrm{Z \alpha ^{2 } \times \mathrm { P } \times \mathrm { Q }}}{\mathrm{d}^{2}} \\
& \mathrm{n}=\frac{1,96^{2} \times 0,54 \times 0,46}{0,05^{2}}=382
\end{aligned}
$$

P: Prevalence of trichuriasis: $54 \%$ (determined from a crosssectional study in Perokonda Village, Sumba Barat Daya District) 


\section{d: Precision rate: $5 \%$}

\section{Confidence interval: $95 \%$ with $\alpha=0.05$ and $Z \alpha=1.96$}

Based on the sample calculation, 382 subjects were required to determine the prevalence of trichuriasis. To determine the effectiveness of albendazole compared with mebendazole, subjects were selected from a cross-sectional survey, as stated above. The number of subjects needed for the RCT was calculated by the formula:

$$
\begin{gathered}
\mathrm{n}_{1}=\mathrm{n}_{2}=\frac{\left(\mathrm{Z} \alpha \sqrt{2 \mathrm{PQ}}+\mathrm{Z} \beta \sqrt{\mathrm{P}_{1} \mathrm{Q}_{1}+\mathrm{P}_{2} \mathrm{Q}_{2}}\right)^{2}}{\left(\mathrm{P}_{1}-\mathrm{P}_{2}\right)^{2}} \\
=\frac{[1,96 \sqrt{2(0,46 \times 0,54)}+0,842 \sqrt{(0,3 \times 0,7)+(0,62 \times 0,38)}]^{2}}{(0,3-0,62)^{2}}=37
\end{gathered}
$$

$\mathrm{Z} \alpha: \mathrm{Z}$ value for type I error risk (1.96 for $\alpha=0.05)$

$\mathrm{Z} \beta$ : Z value for type II error risk ( 0.842 for $\beta=0.80$, two-tailed $)$

$\mathrm{P}_{1}$ : CR of the albendazole-treated group (30\%)

$\mathrm{P}_{2}$ : CR of the mebendazole-treated group (62\%)

$\mathrm{n}$ : number of subjects per group

$P: 1 / 2\left(P_{1}+P_{2}\right)$

Based on the calculation above, 37 subjects were assigned to each group. Subjects were chosen by simple random sampling method, then the selected subjects were randomly separated into two groups: the first group received a triple dose of $400 \mathrm{mg}$ albendazole, and the second group received a triple dose $500 \mathrm{mg}$ mebendazole. The study was single-blinded as stool examiners remained unaware of the grouping or treatment of the subjects.

\section{Data collection}

Subjects and their parents were given information about the study, and informed consent was obtained from the parents. Each subject was given a $10 \mathrm{ml}$ plastic container with a label of their identity. Subjects' parents were asked to fill the plastic container with the subjects' feces and to return it the following day for macroscopic examination (color and consistency) and slide preparation using the Kato-Katz method. The preparation was examined microscopically to identify worm eggs and intensity of infection. Subjects with a positive stool were given a triple dose of either $400 \mathrm{mg}$ albendazole or $500 \mathrm{mg}$ mebendazole based on the assigned group. Fecal examination was conducted again $14 \mathrm{~d}$ after treatment to calculate CR and ERR.

\section{Data analysis}

The proportions of trichuriasis infection and eggs per gram (EPG) before and after intervention were analyzed with McNemar's test and the Wilcoxon test, respectively. CR was analyzed using Fischer's exact test, and ERR was analyzed using the Mann-Whitney test. All data were analyzed with SPSS statistical software version 20.0.

\section{RESULTS}

Table 1 shows the subjects' characteristics based on gender and age. Girls are shown to have a higher proportion of trichuriasis, ascariasis, and mixed infection (trichuriasis + ascariasis). However, regarding the proportion of infection, there is no significant gender difference. Furthermore, subjects were divided into two age categories; 7-9 y old and 10-12 y old. Older children had a higher proportion of trichuriasis and mixed infection, but the proportion of ascariasis infection was the same.

Table 1: Characteristics of the subjects $(n=382)$

\begin{tabular}{llll}
\hline Characteristics & Mixed Infection & T. trichiura & A. lumbricoides \\
\hline Gender & $70(38.3 \%)$ & $46(25.1 \%)$ & $45(24.6 \%)$ \\
Male (n = 183) & $89(44.7 \%)$ & $51(25.6 \%)$ & $69(34.7 \%)$ \\
Female (n =199) & 0.200 & 0.912 & 0.031 \\
Chi squared test, P & & $36(22.2 \%)$ & $57(35.2 \%)$ \\
Age (years) & $68(42.0 \%)$ & $61(27.7 \%)$ & $57(25.9 \%)$ \\
$7-9(\mathrm{n}=162)$ & $91(41.4 \%)$ & 0.222 & 0.051 \\
$10-12(\mathrm{n}=220)$ & 0.905 & $\mathbf{9 7}(\mathbf{2 5 . 4 \% )}$ & $\mathbf{1 1 4 ( 2 9 . 8 \% )}$ \\
Chi squared test, P & $\mathbf{1 5 9 ( 4 1 . 6 \% )}$ & & \\
Total (n= 382) & &
\end{tabular}

Based on sample size calculation, the trichuriasis subjects were divided equally into two groups, each group consisting of 37 subjects. The minimum sample size for both groups was thus 74 subjects. However, because the number of children who fulfilled the study criteria was 97 , all subjects were included in this study and divided into an albendazole-treated group $(n=48)$ and a mebendazole-treated group $(\mathrm{n}=49)$. All subjects in the albendazole group had a light infection, while in the mebendazole group, two subjects had a moderate infection, and the others mostly had mild infections. Criteria intensity of infection above are following WHO [6].

After intervention, seven subjects $(14.6 \%)$ in the albendazole-treated group and two subjects (4.1\%) in the mebendazole-treated group still tested positive for T. trichiura eggs. Both groups showed a significant reduction in the proportion with infection and mean EPG, although the reduction was greater in the mebendazole-treated group. There was a significant reduction in mean EPG in both groups (table 2).

Table 2: Proportion and mean EPG of trichuriasis before and after intervention

\begin{tabular}{lll}
\hline & Albendazole & Mebendazole \\
\hline Proportion, n (\%) & $48(100 \%)$ & $49(100 \%)$ \\
Before & $7(14.6 \%)$ & $2(4.1 \%)$ \\
After & $<0.001$ & $<0.001$ \\
McNemar's test, P & & \\
EPG & $84(24-768)$ & $96(24-8520)$ \\
Before, median (min-max) & $0(0-48)$ & $0(0-48)$ \\
After, median (min-max) & $<0.001$ & $<0.001$ \\
Wilcoxon test, P & & \\
\hline
\end{tabular}

Table 3 presents the CR and ERR of T. trichiura after albendazole and mebendazole treatment. Both drugs have a high CR; mebendazole has a higher CR compared with albendazole, but there is no significant difference in CR between the two drugs. The ERR values of both drugs are similar, with no significant difference between them.
During treatment, there were three adverse reactions: one allergic reaction in the form of urticaria in one subject in the albendazole group, generalized edema in two subjects in the mebendazole group, and the passage of worms from the mouth in four subjects in the mebendazole group. 
Table 3: Cure rate (CR) and egg reduction rate (ERR) of T. trichiura after treatment

\begin{tabular}{llll}
\hline & Albendazole & Mebendazole & RR (95\% CI) \\
\hline CR & $85.4 \%$ & $95.9 \%$ & $0.891(0.782-1.015)$ \\
ERR, mean \pm SD & $96.1 \pm 15.1 \%$ & $99.2 \pm 3.6 \%$ & $0.091^{*}$ \\
\hline
\end{tabular}

*Fisher's exact test, **independent $t$ test.

\section{DISCUSSION}

This study evaluated the effectiveness of triple-dose mebendazole and albendazole in the treatment of trichuriasis. At baseline, trichuriasis was not the only parasitic infection found; ascariasis and mixed infection were also present. This is understandable, given that the study location is one of the most prevalent areas of soiltransmitted helminth (STH) infections. [3] It was found that girls had a higher proportion of STH infection compared with boys in all types of infection. This finding accords with a study in Kenyan school-aged children, in which females had a higher proportion of infection than males.[9] Furthermore, in the present study, older children (10-12 y) had a higher proportion of trichuriasis and mixed worm infection, but not of ascariasis infection. This is also comparable with a study in Ethiopia that found that as children age, the prevalence of infection increases. [10] However, all types of worm infection showed no significant age or gender differences.

In this study, both triple-dose albendazole and mebendazole treatment significantly reduced the proportion of trichuriasis. In the albendazole-treated group, the proportion was reduced significantly by $85.4 \%$ (from $100 \%$ at baseline) to $14.6 \%$ after treatment. A greater reduction was observed in the mebendazole-treated group in which the proportion was significantly lowered by over $90 \%$ (from $100 \%$ at baseline) to $4.7 \%$ after intervention. These results are similar to those reported by Steinmann et al. [7], although we found a greater reduction in the proportion of the disease for both drugs in our study. Mebendazole was found to be the better treatment compared with albendazole, although both agents showed effectiveness in treating trichuriasis.

Mebendazole is more effective in treating trichuriasis because of its greater reduction in the number of EPG despite a higher EPG load at baseline; that said, both drugs were effective in reducing the number of EPG significantly. This result is comparable with results from a study that also showed a better reduction in the number of EPG with mebendazole compared with albendazole, irrespective of dosage (single or triple dose) [7]. A study in Ethiopian schoolchildren showed that triple-dose mebendazole yielded higher CR and ERR compared with single-dose albendazole [11]. A combination therapy using other anthelmintic agents such as ivermectin also demonstrated that combination with mebendazole resulted in higher EPG reduction compared with albendazole [12].

In this study, the CR of albendazole was $85.4 \%$ and that of mebendazole was $95.2 \%$, and the ERR of both drugs was similar (albendazole, 96\%; mebendazole, 99\%). Previous studies have also reported similar values, which supports the superiority of mebendazole compared with albendazole $[7,12]$.

Interestingly, because there was no significant difference in CR and ERR between the two agents, both drugs can be considered effective in treating trichuriasis. A systematic review reported that mebendazole achieved both the highest CR and ERR [19]. Head-tohead regression analysis of CR and ERR differences between albendazole and mebendazole treatment of trichuriasis showed that mebendazole was superior to albendazole [13].

In this study, there were three adverse events in the form of allergic reactions (two subjects in the mebendazole group; one subject in albendazole group). In the mebendazole group, the allergic reaction was generalized urticaria, which had been previously reported as an adverse event, but it is not the most common one [12]. Seven children experienced the passage of adult worms from their mouths (four in the mebendazole group and three in the albendazole group).

It is crucial to better understand the effectiveness of treatment strategies against trichuriasis because it has been shown that trichuriasis infection can affect children's growth and school performance [14]. Another study in Honduras revealed that trichuriasis can lead to anemia, malnutrition, and ultimately growth retardation [15]. Therefore, treating the parasitic infection in children must be prioritized and given special attention, as it affects the future generation of a country.

\section{CONCLUSION}

Triple-dose albendazole and mebendazole are both equally effective in treating school-aged children with trichuriasis. Both groups showed a high CR (mebendazole, 95.2\%; albendazole, 85.4\%) and a high ERR (mebendazole, 99\%; albendazole, 96\%).

\section{DATA AVAILABILITY}

The data used to support the findings of this study are included in the article.

\section{ACKNOWLEDGEMENT}

This article was presented at The $3^{\text {rd }}$ International Conference and Exhibition on Indonesian Medical Education and Research Institute (ICE on IMERI 2018), Faculty of Medicine, Universitas Indonesia, Jakarta, Indonesia. We thank the Directorate of Research and Public Services Universitas Indonesia who funded this research (Grant no. 2126/UN2. R3.1/HKP.05.00/2018). We also thank headmaster and teachers in Panimbang Village, Pandeglang District, Banten Province who assisted this research. We thank the $3^{\text {rd }}$ ICE on IMERI Committee who had supported the peer review and manuscript preparation before submitting to the journal.

\section{AUTHORS CONTRIBUTIONS}

All the author have contributed equally

\section{CONFLICTS OF INTERESTS}

The authors declare no conflicts of interest

\section{REFERENCES}

1. Bethony J, Brooker S, Albonico M, Geiger SM, Loukas A, Diemert $\mathrm{D}$, et al. Soil-transmitted helminth infections: ascariasis, trichuriasis, and hookworm. Lancet 2006;367:1521-32.

2. Woodhall D, Jones JL, Cantey PT, Wilkins PP, Montgomery SP. Neglected parasitic infections: what every family physician needs to know. Am Fam Physician 2014;89:803-11.

3. Sungkar S, Pohan A, Ramadani A, Albar N, Azizah F, Nugraha A et al. Heavy burden of intestinal parasite infections in Kalena Rongo village, a rural area in South West Sumba, eastern part of Indonesia: a cross sectional study. BMC Public Health 2015;15:1296.

4. Sungkar S, Sianturi I, Kusumowidagdo G. Human Infection with Hymenolepis spp: case reports from east Indonesia. Arch Parasitol 2017;1:1.

5. WHO. Preventive chemotherapy in human helminthiasis. Geneva: WHO; 2006.

6. WHO. Soil-transmitted helminth infections; 2017. Available from: http://www.who.int/mediacentre/factsheets/fs366/en/. [Last accessed on 10 Nov 2018]

7. Steinmann P, Utzinger J, Du Z, Jiang J, Chen J, Hattendorf, et al. Efficacy of single-dose and triple-dose albendazole and mebendazole against STH and Taenia spp: a randomized controlled trial. PLoS One 2011:6:1-8.

8. Sungkar S, Asri S Ridwan, Kusumowidagdo G. The effect of deworming using triple-dose albendazole on nutritional status of children in perobatang village, Southwest Sumba, Indonesia. J Parasitol Res 2017. https://doi.org/10.1155/2017/5476739 
9. Mulambalah CS, Ruto J. Prevalence and infection intensity of geohelminthiases on school children as an environmental health indicator to guide preventive activities in Nandi County, Kenya. Trop J Med Res 2016;19:131-7.

10. Khanum H, Mukutmoni M, Uddin J, Haque R. Diarrheal carriage illness with Trichuris trichiura among the slum dwelling children in Dhaka city. Biores Comm 2016;2:254-8.

11. Legesee M, Erko B, Medhin G. Comparative efficacy of albendazole and three brands of mebendazole in the treatment of ascariasis and trichuriasis. East Afr Med J 2004;81:134-8.

12. Knopp S, Mohammed KA, Speich B, Hattendorf J, Khamis IS, Khamis NA, et al. Albendazole and mebendazole administered alone or in combination with ivermectin against T. trichiura: randomized controlled trial. Clin Infect Dis 2010;51:1420-8.

13. Moser W, Schindler W, Keiser J. Efficacy of recommended drugs against soil transmitted helminths: systematic review and network meta-analysis. Br Med J 2017;358:j4307.

14. Simeon D, Callender J, Wong M, Grantham-McGregor S, Ramdath DD. School performance, nutritional status and trichuriasis in Jamaican school children. Acta Pediatrica 1994;83:1188-93.

15. Kaminsky RG, Castillo RV, Flores CA. Growth retardation and severe anemia in children with Trichuris dysenteric syndrome. Asian Pac J Trop Biomed 2015;5:591-7. 